\title{
A Practical Synthesis of (S)- and (R)-4-Hydroxy-2-pyrrolidinone via 1-Phenylethylamine Mediated Resolution
}

\author{
Tae Ho Park, ${ }^{*}$ Seunguk Paik, ${ }^{\dagger, *}$ and Sang Ho Lee \\ Korea Research Institute of Chemical Technology, P.O. Bor 107, Tustung, Daejeon 305-606, Korea \\ ${ }^{\dagger}$ Department of Indistrial Chemistry, Keimving Lniversity, Daegu 704-701, Korea \\ Received April 8, 2003
}

Key Words : 4-Hỵdroxy-2-py rrolidinone. 1-Pheny lethylamine. Methanesulfonic acid. Resolution

The synthesis of natural or unnatural pyrrolidine and pyrrolidinone derivatives has recently attracted considerable interest due to their wide range of biological properties. ${ }^{l}$ A large number of pyrrolidine alkaloids and kamino acids have been prepared by using structurally unique 2pyrrolidinones, which could be utilized as common synthetic subunits and/or chiral templates of biologically active compounds. ${ }^{2}$ In the course of our investigations concerning the synthesis of $\gamma$-aninobutyric acid derivatives which are important in neurobiology: ${ }^{3}$ we have been interested in the synthesis of both enantiomers of 4-hydroxy-2-pyrrolidinone (1), a useful synthetic precursor of a variety of $\gamma$-amino acids (GABA) and pyrrolidinone alkaloids. ${ }^{+} \mathrm{A}$ few reports of the synthesis of the enantiopure pyrrolidinone 1 have been found in literature ${ }^{+56}$ The reported stereoselective syntheses of 1 were mostly involved in the synthetic methods of $(S)$ enantioner of 1 starting from ethyl (S)-4-chloro-3-hydroxybutanoate ${ }^{-}$obtained enzymetically from ethyl 4-chloro-3oxobutanoate, from (S)-4-amino-3-hydroxybutanoic acids, and from (S)-malic acid. ${ }^{4}$ We wish to report herein a practical synthesis of enantionerically pure (R)- and (S)isomers of 1 in multigram scale.

Our synthetic approach involved the preparation of the enantioneric malonamide derivatives 4 bearing a chiral $\mathrm{N}$. phenylethyl moiety for a facile cyclization and the easy separation of the corresponding sec-alcoholic diastereomers
6. followed by deblocking of the chiral moiety as shown on Scheme 1. In order to examine the most appropriate precursor of 1 . two enantiomeric malonamides 4 were prepared from readily available starting materials.

Thus. condensation of half acid of t-butyl malonate $\mathbf{2}$ and glycine esters 3a. b using I, I'-carbony ldiimidazole (CDI) as an activating agent afforded the N-phenylethyl-protected amides $4 \mathbf{a}$. $\mathbf{b}$ in respective yields of 91 and $90 \%$. Cyclization of malonamides $\mathbf{4 a}$ and $\mathbf{t b}$ was readily effected with 1.1 equiv of potassium tert-butoxide in toluene (rt, $5-6 \mathrm{~h}$ ), followed by acdification with $1 \mathrm{~N} \mathrm{HCl}$ to afford white solids of the corresponding 4-oxoamides $\mathbf{5} \mathbf{a}$ and $\mathbf{5} \mathbf{b}$ in excellent yields $(>92 \%)$. It is worth noting that the reaction of $\mathbf{4 a} . \mathbf{b}$ with potassium $t e n$-butoxide in toluene at room temperature gave directly the decarboxy lated 4-oxopyrrolidinones $\mathbf{5 a}$. b without further treatment of the cyclized pyrrolidinones having the $t$-butosycarbonyl group at $\mathrm{C}-3$. Subsequent reduction of the carbonyl group of $\mathbf{5}, \mathbf{b}$, with $\mathrm{NaBH}_{4}$ produced nearly 1 : l diastereomeric mixtures of 4-hydroxypyrrolidinones $\mathbf{6 a}$. $\mathbf{a}^{\prime}$ and $\mathbf{6} \mathbf{b}, \mathbf{b}^{\prime}$ in respective yields of $79 \%$ and $78 \%$. In the courses of several attempted isolations of the diastereomeric mixtures $6 a, a^{\prime}$ and $6 b, b^{\prime}$, we found that one of the diastereomers had a relatively low solubility in acetonitrile and could be isolated by recrystallization from this solvent. Thus. the diastereomeric mixture 6a, a' was readily separated by recrystallization in acetonitrile to give a

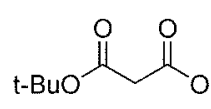

2

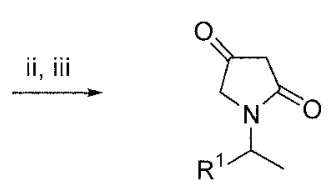

5a: $R^{1}=(R)-P h$

$5 b: R^{1}=(S)-P h$<smiles>[R]C(C)NCC(=O)OCC</smiles>

3a: $R^{1}=(R)-P h$ 3b: $R^{1}=(S)-P h$

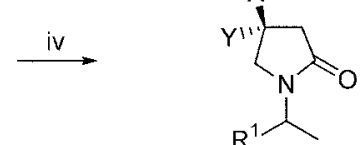

6a: $\mathrm{R}^{1}=(\mathrm{R})-\mathrm{Ph}, \mathrm{X}=\mathrm{OH}, \mathrm{Y}=\mathrm{H}$

6a': $R^{1}=(R)-P h, X=H, Y=O H$

$6 b: R^{1}=(S)-P h, X=O H, Y=H$

$6 b^{\prime}: R^{1}=(S)-P h, X=H, Y=O H$<smiles>[R]C(C)N(CC(=O)OCC)C(=O)CC(=O)OCC</smiles>

4a: $R^{1}=(R)-P h$

$4 b: R^{1}=(S)-P h$

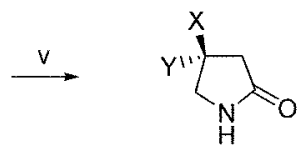

1a: $X=\mathrm{OH}, Y=\mathrm{H}$

1b: $X=\mathrm{H}, Y=\mathrm{OH}$

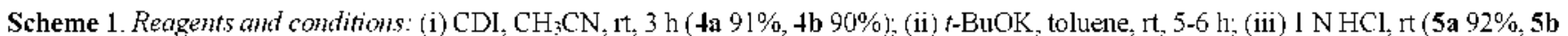

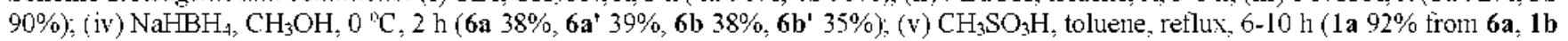
$84 \%$ from $\left.6 a^{*}\right)$. 
white solid (38\%) of (l'R.4S)-4-lydroxy-1-(l'-pheny lethyl)2-pyrrolidinone (6a): ( $\left({ }^{\prime} R, 4 R\right.$ )-pyrrolidinone $6 a^{\prime}$ was obtained in $39 \%$ yield after chromatographic separation on silica gel of the remaining residue. "Under nearly identical condition, (l'S, 4 S)-pyrrolidinone $6 \mathbf{b}$ was also obtained in $38 \%$ yield; chromatographic separation on silica gel of the remaining residue yielded ( $l$ S, $4 R$ )-pyrrolidinone $6 b^{\prime}$ in $35 \%$ yield. ${ }^{9}$ In the funal step, deprotection of the N-phenylethyl blocking group of pyrrolidinones 6 was required. It has been generally hnown that $\mathrm{N}-(1$-phenylethyl)amines and $\mathrm{N}$ (1-phenylethyl)amides are less susceptible to catalytic hydrogenolysis than benzyl ether and benzyl esters, and hydrogenolysis of benzylamines and benzylamides can be facillitated by acid. ${ }^{7}$ Moreover. Frahm and co-workers recently reported $\mathrm{N}$-(l-phenylethyl)-protected $\alpha$-aminonitriles were readily converted to the corresponding carboxamides with conc. $\mathrm{H}_{2} \mathrm{SO}_{4}$ at $25^{\circ} \mathrm{C}$ resulting in a total loss of the 1-phenylethyl moiety. ${ }^{8}$ Based on this information about the sensitivity of the $\mathrm{N}$-pheny lethyl moiety of amines and amides under acidic conditions, deprotection of the 1-phenylethyl moiety in $6 \mathrm{a}$ and $6 \mathrm{~b}$ was surprisingly accomplished through use of methanesulfonic acid in toluene. Thus, treatment of $6 \mathrm{a}$ and $6 \mathrm{a}^{\prime}$ in refluxing toluene in the presence of 5 equiv of methanesulfonic acid for $5-6 \mathrm{~h}$ afforded the final enantiopure $1 \mathrm{a}$ and $1 \mathrm{~b}$ in respective yields of 92 and $84 \%$ after chromatographic separation on silica gel. To our knowledge. this is the first example of highly efficient removal of the $\mathrm{N}$ phenylethyl group on anides using metanesulfonic acid.

In sunmary. we have described a practical route of the preparation of both (R)- and (S)-4-hydroxy-2-pyrrolidinone from a single precusor $+\mathbf{a}$ or $+\mathrm{b}$ through use of $\mathrm{N}$ phenylethyl-mediated resolution of pyrrolidinones 6 in respective overall yields of 32 and $30 \%$ starting from 4 a via 6a. a'.

8

Acknowledgements. The authors wish to thank the Ministry of Science and Technology and the Ministry of
Commerce. Industry and Energy for financial assistance. The authors also thank the Korea Science and Engineering Foundation through the Center for Traditional Microorganism Resources (TMR) at Keimyung University

\section{References and Notes}

1. (a) Murnata. A.: Ibuka. I. In The Alkalodes. Brossi. K.. Ed.: Academic Press: New York. 1987: Vol. 31, Chapter 6. (b) Lin, N.H. Carrera, G. M., Jr.: Anderson. D. J. Med. Chem 1994, 37 3542. (c) Paik, S.; Kwak. H. S.; Park. T. H. Bull. Korean Chen. Soc. 2000.21 .131$.

2. Banziger. M.: McGarrity. T. F.: Meul. T. J. Ong Chent 1993. 58. 4010. (b) Miyamoto. S.: Mori. A. Newosciences 1985. 11. 1.

3. (a) Kainie Acids as a Tool in Neurobiology; Megeer, E. G.; Olney, J. W: MoGeer. P. L., Eds.: RavenPress: New York, 1978. (b) Renauh. P.: Seebach, D. Swthesis 1986. 424. and references cited herein.

4. (a) Huang. P. Q.: Wang. S. L.: Ye. T. L.: Ruan1. Y. P: Huang. Y. Q: Zheng. H.: Gao. T. X. Tetrahedron 1998. 54. 12547. (b) Haung. P. Q: Zheng, X; Wang. S. L; Ye, J. L; Jin, K. R; Chen, Z. Tetrahedron: Aswmetry 1999. 10,3309.

5. Santaniello. E.: Sasati, R.: Milani, F. J. Chem. Research (S) 1984. 132.

6. Pellegata. R.: Pinza. M.: Pifferi. G. Swnthesis 1978.614.

7. Goldstein. S. W.: Overman. L. E.: Rabinowitz. M. H. J. Ong Chem $1992,57,1179$.

8. Pai Fondekar, K. P.: Volk, F. J.: Khaliq-uz-Zaman, S. M.; Bisel, P: Frahm. A. W. Tetrohedron: Asymmetry 2002, 13. 2241.

9. Data for 6. 6a: $\left[(x]^{18}=+118.8^{\circ}(\mathrm{c} 1.0 . \mathrm{EtOH})\right.$ : ${ }^{\mathrm{H}} \mathrm{H} \mathrm{NMR}(500) \mathrm{MHz}$. $\left.\mathrm{CDCl}_{3}\right) \delta 7.33-7.25(5 \mathrm{H} . \mathrm{m}) .5 .46(1 \mathrm{H} . \mathrm{q} . J=7.1 \mathrm{~Hz}) .4 .43(1 \mathrm{H}$. mi). 3.52 ( $1 \mathrm{H}$. dd. $J=10.8 .5 .5 \mathrm{~Hz}$ ). 2.95 (1H. dd. $J=10.8 .2 .0$ Hz). $2.68(1 \mathrm{H} . \mathrm{dd} . J=17.3 .6 .5 \mathrm{~Hz}) .2 .39(1 \mathrm{H} . \mathrm{dd} . J=17.3 .0 .5$ $\mathrm{Hz}) .1 .48(3 \mathrm{H}, \mathrm{d} . J=7.2 \mathrm{~Hz}):{ }^{13} \mathrm{C}$ NMR $\left(125 \mathrm{MHz}, \mathrm{CDCl}_{3}\right) \delta$ $172.4,139.9,128.5,127.4,126.9,64.3,51.5,48.7,41.5 .16 .5 .6 a^{\prime}:$ $[\alpha]^{8}=+177.6$ (c 1.0. EtOH): ${ }^{\prime} \mathrm{H}$ NMR $\left(500 \mathrm{MHz} . \mathrm{CDCl}_{3}\right) \delta$ $7.34-7.26(5 \mathrm{H} . \mathrm{m}) .5 .50$ (1H. q. $j=7.1 \mathrm{~Hz}) .4 .40(1 \mathrm{H}$. brs $) .3 .34$ (IH. s). 3.26 (IH. dd. $J=10.8 .2 .4 \mathrm{~Hz}$ ). 3.20 (IH. dd. $J=10.8$. $5.6 \mathrm{~Hz}) .2 .69(\mathrm{lH} . \mathrm{dd} . J=17.3 .6 .6 \mathrm{~Hz}) .2 .43(1 \mathrm{H} . \mathrm{dd} . J=17.3$. $2.7 \mathrm{~Hz}), 1.55(3 \mathrm{H}, \mathrm{d} . d=7.1 \mathrm{~Hz}):{ }^{13} \mathrm{C}$ NMR $\left(125 \mathrm{MHz}, \mathrm{CDCl}_{3}\right)$ $\delta 173.3,140.6 .129 .3 .128 .4 .127 .8,64.7,51.7,49.1,41.8,16.2$. 6b: $[o]^{18}=-177.6^{\circ}$ (c 1.0. EtOH). 6b': $[o]^{18}=-118.8^{\circ}$ (c l.o. $\mathrm{EtOH}$. 